\title{
NOTE ON A CASE OF ANASTHESIA.
}

BY н. B. DONKIN, M.B. (OXON.), F.R.C.P.,

Physician to Westminster Hospital, and to East London Hospital for Children.

THE greater difficulty of establishing the existence and assessing the value of modifications of sensation than of motion as symptoms of nerve-disturbance is of course obvious. Not unfrequently, however, this point is overlooked in reporting cases, and even in drawing important inferences from alleged accounts of sensory abnormalities. At first sight it seems clear that heightened or lowered sense-functions in human beings, depend very largely for the evidence of their existence on the statement of the patient: or in other words are to a great extent "subjective :" while motor disturbance, whether it be in the direction of spasm or paralysis, is much more open to observation or demonstration, and may generally be regarded, with certain limits and precautions, as an "objective " symptom. We all know that a great power of control over the expression of pain or pleasure is possessed by many persons : and that, within the bounds of obvious nervous health, there is often shown a capacity of bearing with apparent indifference the infliction of what most would undoubtedly regard as pain, not to mention the extreme sensibility of others to stimuli which most would ignore as indifferent. Instances of this are too numerous to necessitate quotation. Notwithstanding these facts, it is not uncommon to find the patient's mere statement of heightened or lost sensation, in certain conditions, or after certain applications or remedies, received even by skilled investigators as of equal symptomatic value with demonstrable alterations of motility. Some of the French writings on the neurology of sensation, especially those which deal with the phenomena of anesthesin as related to "motallo-" and 
"magneto-therapy," are notable instances of apparént neglect of the possible vicious intervention of this fallacy in the experiments which they detail and regard as of so great importance.

At the bottom of this constantly occurring confusion in medical and psychological writings, as, indeed, at the bottom of a vast majority of controversies in general, lies a want of clearness of conception of the thing to be expressed, and still more a want of precision in the terms used to express it. In psychology there is an ever-recurrent danger of using physical and psychical terms interchangeably, and in a slip-shod, and sometimes almost disingenuous manner. It would indeed be well in the interests of true physiological psychology if the term consciousness could be altogether abolished, for thus a large amount of metaphysical haze would be dispelled. But perhaps this. desirable expurgation of our terminology cannot be made. The term sensation though in its physiological application to the sensory nerves, for instance, it stands, or should stand, for the conductivity of impressions from the periphery to an ascending series of centres, is frequently confused with the results of this nervous action as expressed in the feeling (or the consciousness) of the individual. Centripetal nerve action should be kept in our minds quite apart from "conscious" sensation which is the result of some metabolic activity in the higher centres; and if we must use any derivatives of the familiar words "sense" and "conscious" in this context, let us never lose hold of the fact that unconscious sensibility, or unfelt centripetal nerve action, is one thing, and conscious sensibility, or true "feeling," is another. The occurrence, then, of apparent anæsthesia may be regarded as possibly due to an interference with any part of the centripetal nervous apparatus, from the periphery up to the highest sensorial centres.

It should be the primary object in endeavouring to establish or fix the import of any alleged case of anæsthesia, for instance, to eliminate as much as possible the volitional element. Reported anæsthesia may be due, first, to shamming; secondly, to a preconceived mental impression or expectant attention; thirdly, to a mixture of these two elements; and fourthly, may be quite independent of these agencies, and strictly 
called physical. How the tendency towards shamming pure and simple is often allied with Hysteria, and how difficult it is sometimes in a given case to disentangle the passive from the volitional factor in the symptom we are studying, is familiar to all who are conversant with nerve-disorders. It is certainly most incorrect and culpable to put down the bulk of hystericonervous symptoms to shamming : many of the most distressing expressions of hysterical disease being as completely beyond the control of the will as the pain felt by most ordinary persons on the extraction of a tooth. But it is a wide jump from this position to the belief that mental influence on the body plays but an insignificant part in the production of abnormal senseimpressions. Many observers have now placed it beyond doubt that, in cases where mere shamming conld be with the greatest probability excluded, expectant attention can be substituted to a very great extent for the older and vague belief, of late galvanized into a sort of pseudo-vitality in France, in some special influence of metals and magnets on the sense-functions. The experimental methods of "difference" and "concomitant variations," by the use of widely varying applications, in competent hands, have demonstrated the mental factor in many of these cases, thus adding only fresh instances to the numbers already accumulated in such writings as those of Braid, Carpenter, Hack Tuke and others on the influence of the mind upon the body. Yet, erroneous as it may be to refer such cases as many of those reported by $M$. Charcot and his school to shamming rather than to expectant attention, it is not uncommon to meet with examples of the great difficulty there is in separating these two elements, or, indeed, in establishing the fact of genuine anæsthesia at all; and, when we think we have established it, of coming to a probable conclusion as to the presence or the proportion of controllable elements in its production. I give the following condensed account of a somewhat remarkable and interesting case in illustration of this difficulty.

Robert Warne, aged nearly 13, was admitted under my care at the East London Children's Hospital on October 18, 1882.

The account of his previous condition, as obtained from the mother, vas that he had had measles, scarlet fever, and 
whooping-congh, and had suffered much from worms; no diphtheria, or other complaint. Three years before admission be fell down stairs and hurt his chin, since when, his mother says, he has from time to time complained of his head. A fortnight before admission he said he had a pain in his head, which spread down his back and right side, and he lost power in his right arm for quite five minutes. Five days before admission he is said to have had a fit in the night: his "limbs shook and his skin was discoloured." His right thigh also was said to be swollen, and he did not get up next day.

A few days before admission he suddenly fell down, as he was carrying a pail of water. He has never lost his senses, it appears; though he falls down soméimes and feels very faint.

The family history shows that his father has occasionally " "fits," which are apparently epileptic.

On admission, the boy appeared to be quite well. There was no complaint or evidence of any motor disturbance; nor did a careful investigation of his organs and functions show anything abnormal beyond what follows.

The only complaint he makes is that of some pain and tenderness on the outer surface of the right thigh, and complete loss of feeling in his thumb. He says he sometimes sees everything red.

Examination showed apparently complete anasthesia of the skin of the thumb on both aspects: the area involved being exactly limited by a line passing over the carpo-metacarpal joint. The pain in the thigh was not accounted for by examination, and soon passed off entirely. Over the rest of the body the sensation appeared to be good. The tests repeatedly usel to the insensitive thumb, and often when the boy was off his guard, were pressure, pricking, pinching, the approximation of a lighted match to the skin, thrusting a needle under the nail and the use of the faradic current.

Subsequent and frequent examinations up to the end of November showed nothing fresh, except that it was thought that he was somewhat indifferent to ordinarily painful sensations over the borly generally; though he felt the slightest touch, he said that pinching and pricking did not 
hurt much. There was possibly some little sensibility to the faradic current in the thumb-especially, as it seems, at the tip, but this phenomenon was not easy to establish. This possibility rested only on a slight twitch of the thumb, accasionally, when the current was applied. The boy denied feeling it. He had a slight discharge from his right ear, with some pain which soon disappeared. He was out of bed every day after admission, making no complaint.

On December 5th he complained of headache, and did not get up. The temperature remained normal. On the 6 th he said he had pains in the lower part of his legs. On the 7 th there appeared, on examination, to be perfect anesthesia of both legs from the soles of the feet up to a line one and a-half inches above the upper margin of the patella. This limit of anisthesia was repeatedly verified afterwards, the boy being carefully blindfolded, and was tested by the application of all the methods above mentioned of exciting sensation or of inflicting pain.

The boy could walk well, and could stand in any position with his eyes shut without staggering. He said he could not feet the ground at all when walking or stamping; but when the hand was placed under his foot as he stamped, he said he could feel his thigh going up. His knee-jerk was somewhat excessive; no ankle-clonus. The hearing through the skull was good on both sides. On the right side the hearing by the meatus was impaired. He had been subject to a discharge from this ear, off and on, and the tympanic membrane was ruptured. Sight quite good. Colours and objects were accurately distinguished: and the optic disks were healthy in appearance. As to smell, he said, being tested, that "Eau de Cologne" and "Jockey Club" smelt nice in the left nostril, nasty in the right; and he stated that he could taste salt, \&c., only on the left side of the tongue anteriorly, not at all on the right. Sensation to pricking was good all over the tongue.

This case was informally shown for me; by the kindness of a colleague, at a meeting of the Medical Society on Dec. 18, 1882 , in order that others might verify the symptoms, which it was thought might disappear as suddenly as they had appeared. 'The conditions reported above were then ascertained to be present. 
On Jan. 3rd, 1883, the boy, still in hospital, remained the same in every respect: a blister was applied to his right thumb, with no effect on the anæsthesia. He was then sent home.

Qn a visit to the Hospital on Jan. 28, it was found, by the same tests as before, that he had now loss of sensation on the ulnar side of right hand and little finger. This area of anæsthesia extended half-an-inch on to the back and palmar aspect of the hand.

On Feb. 8 I saw him again. He said that since the 5th he had had giddiness and headache, and felt as if everything were turning round him. On the 2 nd, when lifting his arm to comb his hair, he had pain in left shoulder preventing him from doing so. On the $3 \mathrm{rd}$, he says he could not raise his arm. The pain is now less. Anæsthesia the same as before.

In the month of April, 1883, I gained admission for this boy into the London Hospital, in order that his condition might ${ }^{\circ}$ be observed by Dr. Hughlings-Jackson. On the day of admission, as appears from the notes kindly sent us by the clinical clerk in charge of the cases the condition was the same as has been already reported. On the 14th, "the patient stated that the anæsthesia of the little finger had disappeared."

"On the 16th a strong faradic current was tried on legs, one pole being placed on his spine and the other on a portion of the anæsthetic area of one leg. Though he said at first that he did not feel it, it was evident by his expression that he did, and that he was trying to bear it. On slightly increasing the current his fortitude gave way, and he shouted out with the pain; which, however, on being questioned, he referred to the back and hip of the same side."

"On the 17th, he stated, the first thing in the morning, that sensation had returned in his legs; and, being tested with the rsthesiometer, sensation was found to be perfectly normal in the previously anæsthetic areas. The faradic current was then tried on the thumb. At the first application he declared that sensation had suddenly returned to that region. One minute previously, according to his statement when the asthesiometer was used, the anæsthesia was as complete as on admission. (On testing his sense of smell and taste, soon after admission, they were found to be quite normal.) In speaking of the recovery of sensation in his legs, he said, the next morning, that he was 
suddenly awakened in the night with shooting-pains in his legs, and these soon left; a feeling of soreness remaining, and sensation being restored."

The case was said to be regarded from the first by. Dr. Jackson as one due to " constructiveness."

The result of this case in perfect recovery, in circumstances such as have been detailed, certainly points with some plausibility to shamming as its causo; or, at least, as an element in its causation; and it might be supposed that the boy preferred residence in the Children's Hospital, where he had boys of his own age to play with, and, making himself useful, was a favourite in the ward, to going to school or being in the London Hospital. Yet, it did not appear in any way from his history that he disliked school or home; he did not seem anxious to stay in hospital, or to be considered as an invalid; and there was no evidence of any moral depravity or of hysterical tendency. The boy appeared in every way well and normal, with the exception of his apparent anæsthesia. And, it must be remembered too, that, with the hypothesis of shamming, we have to take into consideration the undoubted and often established fact of there having been frequently no signs or expression of sensation, on the application of what to most of the physically bravest men would be simply torture, and the long remaining exact limitation of the anæsthetic areas, as established by careful and repeated testing, when the patient was blindfolded, and with many other precautions. The anæsthesia of the legs was especially unvarying the whole time he was under observation at the Children's Hospital. On admission to the London Hospital, observations made to map out the area of anzsthesia of the thumb were said to be incongruous and contradictory, and "certainly to point to constructiveness."

If the case may be regarded as one of malingering, the absence of obvious motive is not so interesting as the complete control shown over the expression of suffering; a fact, if it be a fact, of enormous importance in studying the symptomatology of nervous disease, and in connection with all alleged cases of somnambulism, hypnotism, metallo-therapy, \&c.

The theory of expectant attention will not satisfactorily cover 
the case, as all the symptoms were spontaneously complained of by the patient himself.

The elimination of the volitional element altogether leaves the case as an obscure one of organic or more probably, seeing that it speedily recovered, of functional anæsthesia. The distribution of the anæsthesia is, however, not after the pattern of recognised cases. It may occur to some that the application of the faradic current had some specific agency in restoring the sensation, especially as there was some little doubt as to whether, from the first, he could not feel the current when applied to his thumb.

Much of the interest of the case lies in the incongruity of the apparent physical phenomena with the theory of the moral obliquity of the patient. If this boy was shamming anæsthesia when he preserved a perfectly passive countenance as a needle was thrust under his nail, what test shall we apply for the numerous cases of alleged anæsthesia which we see and hear of in neurological cliniques, especially those of Paris? And, on the other hand, we may almost raise the question, what was the sensory condition of the Christian martyrs at the stake, or of the Spartan boy with the fox concealed in his bosom?

It seems on the whole more reasonable to conclude, in the present state of our knowledge, and keeping in view the salient facts of the case, that there was really a want of conscious sensibility in this boy, due either to a torpid condition of the sensitive nervous plexuses in those regions of the periphery where stimulation failed to produce its usual effects, and therefore to suspended centripetal conductivity, or to a disordered condition of the sensorium. The former hypotheses appear most probable, when we consider the distribution of the anæsthesia over both legs, the absence of any further abnormal symptoms referable to the cerebrum and the rapid recovery on the application of a strong faradic current. And though other so-called hysterical phenomena were not apparent, the case may perhaps be referred to the same category as some of the sensory disturbances so often seen in confessedly hysterical subjects.

It may be remarked, before leaving this case, that the boy 
complained of feeling pain in his legs both at the onset and before the disappearance of the alleged anæsthesia, and moreover that he appears to have been the probable subject of some form of epilepsy, especially when his father's attacks of "fits" are borne in mind. I cannot attempt a further explanation, but I find it hard to believe that the theory of shamming can explain the case away.

In connection with the subject of modified sensations in relation with mental states, the following case, quoted in Dr. Carpenter's work on Mental Physiology, from a Paper by the late Professor Hughes Bennett on the "Mesmeric Mania of 1881," is of some interest. A butcher was brought into the shop of a druggist, labouring under a terrible accident. The man, in trying to hook up a heavy piece of meat above his head slipped, and the sharp hook penetrated his arm, so that he himself was suspended. On being examined he was pale, almost pulseless, and expressed himself as suffering acute agony. The arm could not be moved without causing excessive pain, and in cutting off the sleeve he frequently cried out; but when the arm was exposed it was found to be quite uninjured, the hook having only touched the sleeve of his coat. "No evidence," says Dr. Carpenter, " could be stronger than that afforded by the almost pulseless condition of the patient, as to the reality of the severe pain which he experienced : and yet the pain entirely arose from his mental conviction that the hook had penetrated the flesh of his arm." This case may be compared with the alleged "sensitiveness," to what was called "odylic force," reported long ago by Reichenbach in connection with his experiments with magnets on human beings. 